\title{
Epoxyeicosanoids in Hypertension
}

\author{
J. D. IMIG ${ }^{1}$ \\ ${ }^{1}$ Department of Pharmacology and Toxicology, Cardiovascular Center, Medical College of \\ Wisconsin, Milwaukee, WI, USA
}

Received August 26, 2019

Accepted August 28, 2019

Epub Ahead of Print September 2, 2019

\begin{abstract}
Summary
Epoxyeicosatrienoic acids (EETs) are also known as epoxyeicosanoids that have renal and cardiovascular actions. These renal and cardiovascular actions can be regulated by soluble epoxide hydrolase ( $\mathrm{SEH}$ ) that degrades and inactivates EETs. Extensive animal hypertension studies have determined that vascular, epithelial transport, and anti-inflammatory actions of EETs lower blood pressure and decrease renal and cardiovascular disease progression. Human studies have also supported the notion that increasing EET levels in hypertension could be beneficial. Pharmacological and genetic approaches to increase epoxyeicosanoids in several animal models and humans have found improved endothelial vascular function, increased sodium excretion, and decreased inflammation to oppose hypertension and associated renal and cardiovascular complications. These compelling outcomes support the concept that increasing epoxyeicosanoids via $\mathrm{sEH}$ inhibitors or EET analogs could be a valuable hypertension treatment.
\end{abstract}

\section{Key words}

Epoxyeicosatrienoic acid • Natriuresis • Endothelium • Sodium channels

\section{Corresponding author}

J. D. Imig, Department of Pharmacology \& Toxicology, Medical College of Wisconsin, 8701 Watertown Plank Road, Milwaukee, Wisconsin 53226, USA. E-mail: jdimig@mcw.edu

\section{Introduction}

Hypertension is the most prevalent cardiovascular disease that afflicts one in every three adults worldwide (Barri 2008, Mills et al. 2016). Several factors contribute to the chronic blood pressure elevation which increases the risk for cardiovascular morbidity and mortality. Contributing factors to hypertension include an elevated renin-angiotensin system, increased sympathetic activity, and inflammation (Imig et al. 2018, Kaplan 2016). These factors result in excessive vasoconstriction and increased total peripheral resistance or impaired sodium excretion, increased extracellular fluid volume, and increased cardiac output (Imig et al. 2018). Antihypertensive drugs counteract these contributing factors and include renin-angiotensin system inhibitors, $\beta$-blockers, vasodilators, and diuretics (Chobanian 2003, Kaplan 2016). These therapies have been largely successful in lowering blood pressure in hypertension; however, evidence suggests that antihypertensive treatment is suboptimal since cardiovascular morbidity and mortality remains a significant health care problem (Chobanian et al. 2003, Kaplan 2016, Munter et al. 2014). Research continues to identify novel contributing factors to blood pressure regulation that could improve hypertension treatment and decrease cardiovascular mortality. Contributing factors to blood pressure regulation that have garnered significant attention are the epoxy fatty acids, epoxyeicosatrienoic acids (EETs) and their metabolism by soluble epoxide hydrolase (sEH) (Capdevila and Wang 2013, Imig 2012).

EETs are twenty carbon epoxy fatty acids also known as epoxyeicosanoids. EETs are generated from arachidonic acid by cytochrome (CYP) P450 epoxygenases. CYP2C and CYP2J enzymes produce four regioisomeric EETs; 5,6-EET, 8,9-EET, 11,12-EET, and 
14,15-EET (Capdevila and Wang 2013, Imig 2012). EETs are produced and have activities in endothelial cells, kidney, heart, and other organs that impact blood pressure regulation (Capdevila and Wang 2013, Imig 2012). Blood pressure regulating EET actions include vasodilation, increasing sodium excretion, and decreasing inflammation (Bellien and Joannides 2013, Imig 2015). These EETs are then metabolized by $\mathrm{sEH}$ to dihydroxyeicosatrienoic acids (DHETs) that have reduced or no biological activity (Fig. 1) (Imig 2012, Imig 2018). Genetic variations in the sEH gene EPHX2 that increase sEH activity have been demonstrated to cause impaired endothelial vasodilator responses in humans (Bellien and Joannides 2013, Lee et al. 2011). Likewise, human studies provide evidence that decreased EET levels result in an elevated blood pressure. CYP2C epoxygenase enzyme gene variants demonstrate reduced EET generation and increased risk for essential hypertension (Dreisbach et al. 2005, King et al. 2005, Polonikov et al. 2008, Yu et al. 2004,). Attractively, increasing EET levels in hypertension animal models results in blood pressure lowering and cardiovascular protective actions (Campbell et al. 2017, Imig and Hammock 2009).

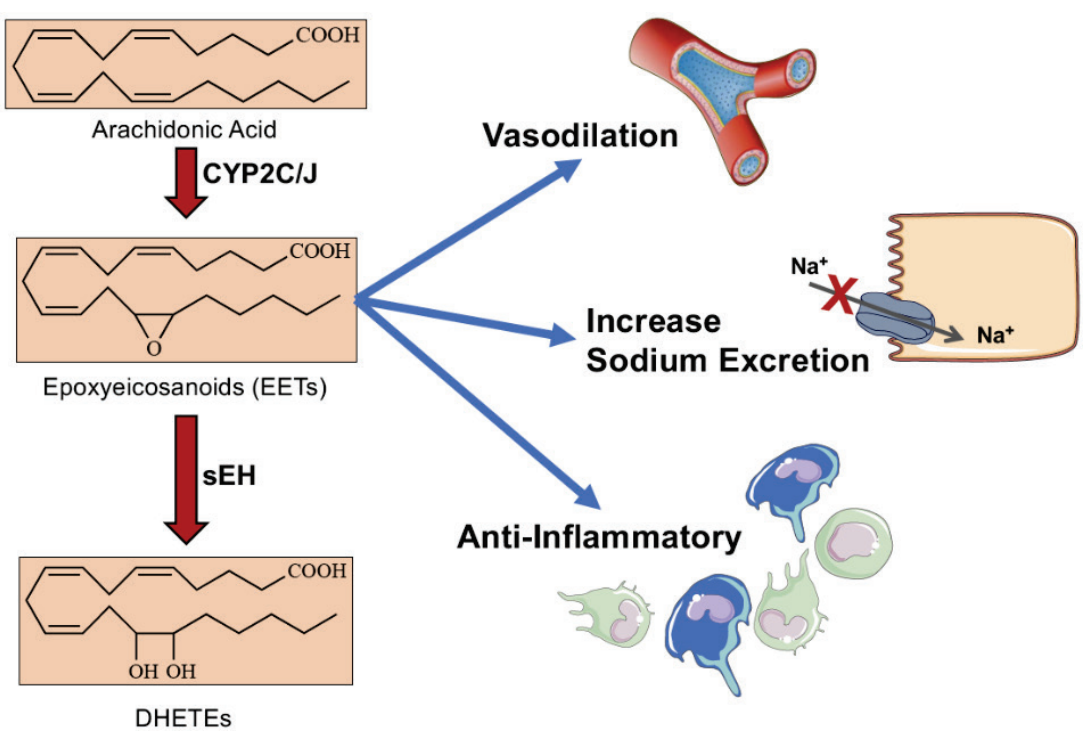

Fig. 1. Epoxyeicosanoids have vasodilator, natriuretic, and anti-inflammatory activities. Left panel illustrates the arachidonic acid metabolism by CYP2C or CYP2] epoxygenase enzymes to epoxyeicosatrienoic acids (EETs) and metabolism of EETs by soluble epoxide hydrolase (sEH) to dihydroxyeicosatrienoic acids (DHETs). Right panel illustrates epoxyeicosanoid actions to cause vasodilation, increase sodium excretion, and combat inflammation.

\section{Epoxyeicosanoids and vascular regulation in hypertension}

Excessive vasoconstriction in hypertension increases total peripheral resistance and decreases renal blood flow that results in impaired sodium excretion. Although elevated angiotensin II levels are a main contributing factor, other factors that cause excessive vasoconstriction in hypertension include elevated endothelin, increased thromboxane, decreased endothelial nitric oxide, and reduced endothelial EET levels (Imig et al. 2018). Reduced nitric oxide and EET levels are major reasons for endothelial dysfunction in hypertension (Bellien et al. 2012, Imig et al. 2018, Lee et al. 2011). Endothelial dysfunction in hypertension and other cardiovascular diseases is associated with poor health outcomes (Baylis 2012, Imig et al. 2018, Montezano and Touyz 2012). Extensive evidence in hypertension animal models provides support to the notion that increasing epoxyeicosanoid EETs improves endothelial function and lowers blood pressure in hypertension (Campbell et al. 2017, Imig 2018, Imig and Hammock 2009).

EETs are endothelial-derived hyperpolarizing factors that ensure proper resistance artery and arteriolar function (Campbell et al. 1996, Fissthaler et al. 1999, Imig et al. 1999). 11,12-EET and 14,15-EET are generated by the endothelium and dilate arterioles through activating vascular smooth muscle cell largeconductance calcium-activated $\mathrm{K}^{+}\left(\mathrm{K}_{\mathrm{Ca}}\right)$ channels (Imig et al. 1999, Imig et al. 2008). Endothelial EET levels are decreased in several hypertension animal models (Imig et al. 2002, Zhao et al. 2003). The decrease in vascular endothelial levels is a consequence of decreased CYP2C11 and CYP2C23 expression in obese Zucker and high fat fed rats that have hypertension (Zhao et al. 2005). On the other hand, angiotensin-dependent hypertension is associated with increased vascular sEH expression that leads to decreased EET levels (Imig et al. 2002). Endothelial dysfunction in angiotensin-dependent hypertension is due to decreased vascular EET levels 
(Imig et al. 2002). Increasing EET levels with sEH inhibition improves endothelial dysfunction in rodent obesity, metabolic syndrome and hypertension models (Campbell et al. 2017, Imig and Hammock 2009). Remarkably, humans that are obese smokers with chronic obstructive pulmonary disease (COPD) and treated with an sEH inhibitor for two weeks demonstrated improved endothelial function (Yang et al. 2017). These findings support the notion that increasing EET levels will improve endothelial function and cardiovascular morbidity and mortality in hypertension.

\section{Hypertension, kidney function and epoxyei- cosanoids}

A decrease in renal epoxygenase activity has been strongly linked to hypertension including angiotensin-dependent and salt-sensitive hypertension (Imig 2018, Imig et al. 2002, Zhao et al. 2003). Rats overexpressing human renin and angiotensinogen genes (dTGR) have decreased renal epoxygenase activity and kidney CYP2C11 and CYP2C23 protein levels (Kaergel et al. 2002). Angiotensin-dependent hypertension is also associated with increased renal sEH protein expression (Imig et al. 2002). Regarding salt regulation, rodent kidney CYP2C epoxygenase enzymes are upregulated in response to a high-salt diet (Lee et al. 2010, Makita et al. 1994, Zhao et al. 2003). Conversely, an inability to upregulate CYP2C epoxygenases in response to a highsalt diet leads to impaired sodium excretion and saltsensitive hypertension (Lee et al. 2010, Makita et al. 1994, Zhao et al. 2003). Taken together, decreased kidney EET levels impairs vascular and epithelial function and contributes to the elevated blood pressure and progression of hypertension.

Extensive evidence in hypertension and renal disease studies demonstrates an important contribution for EETs in maintaining kidney vascular and epithelial function (Capdevila and Wang 2013, Imig 2012, Imig 2018). EETs act to dilate preglomerular afferent arterioles and inhibit epithelial sodium channels $(\mathrm{ENaC})$ (Campbell et al. 2017, Imig 2018). Decreased EET levels in hypertension leads to excessive afferent arteriolar constriction and enhanced $\mathrm{ENaC}$ activity and salt absorption (Fig. 2) (Capdevila et al. 2014, Zhao et al. 2003). Angiotensin-dependent hypertension has increased afferent arteriolar constrictor reactivity that contributes to impaired natriuresis (Zhao et al. 2003). Excessive afferent arteriolar constrictor reactivity in hypertension is eliminated by $\mathrm{sEH}$ inhibition to increase kidney EET levels (Zhao et al. 2003, Zhao et al. 2004). Increased $\mathrm{ENaC}$ in angiotensin-dependent hypertension also contributes the sodium retention and increase in blood pressure (Khan et al. 2014). Salt-sensitive hypertension occurs when the kidney and vascular CYP2C23 and CYP2C11 fails to increase in response to a high-salt diet (Zhao et al. 2003, Zhao et al. 2004). In accordance with these findings, genetic deletion of Cyp2C23 (Cyp2c44) in mice results in decreased kidney and vascular EET levels and salt-sensitive hypertension (Capdevila et al. 2014, Imig 2012, Sun et al. 2010). Indeed, 11,12-EET can inhibit cortical collecting duct $\mathrm{ENaC}$ and increase sodium excretion (Capdevila et al. 2014). Increasing EETs can lower blood pressure by inhibiting sodium absorption in the proximal tubule and cortical collecting duct. (Capdevila et al. 2014, Khan et al. 2014) Taken as a whole, EETs have antihypertensive actions on the renal afferent arteriole and epithelial sodium transport.

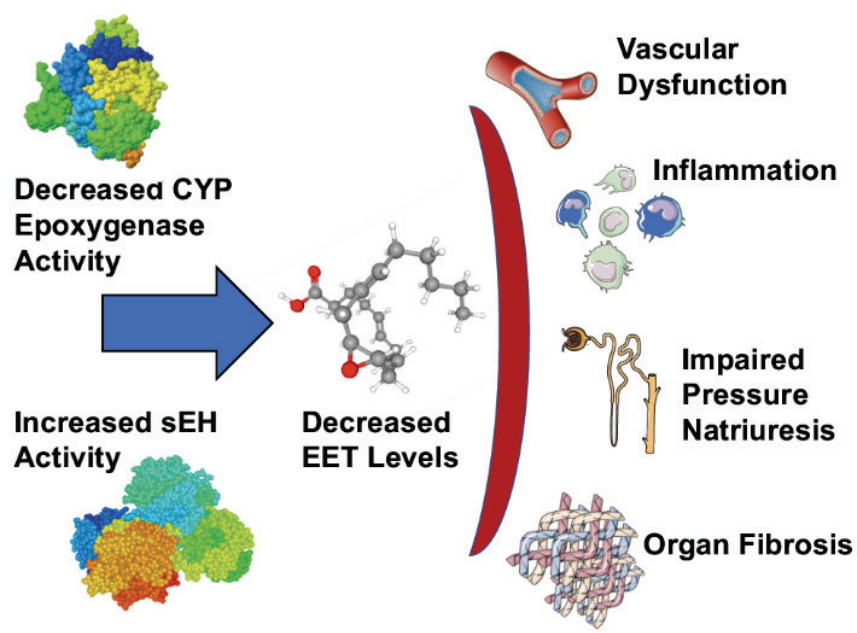

Fig. 2. Decreased epoxyeicosatrienoic acid (EET) levels result in hyper-tension and renal and cardiovascular (CV) complications. Left panel illustrates decreased CYP epoxygenase or increased soluble epoxide hydrolase (SEH) activity leads to decreased EET levels. Right panel illustrates vascular dysfunction, inflammation, impaired pressure natriuresis, and organ fibrosis because of decreased EET levels. These changes in vascular function, inflammation, kidney function, and fibrosis contribute to hypertension and renal and CV disease progression. 
Anti-inflammatory actions of epoxyeicosanoids

Inflammation is a key contributor to hypertension, cardiovascular diseases, and kidney diseases (Harrison et al. 2011, Viel et al. 2010). Vascular and kidney inflammation have been implicated in several hypertension animal models (Harrison et al. 2011, Imig and Ryan 2013, Viel et al. 2010). Elevations in kidney $T$ cells and cytokines like tumor necrosis factor- $\alpha$ (TNF- $\alpha$ ) were reported to contribute to angiotensindependent hypertension and Dahl salt-sensitive rat hypertension (Harrison et al. 2011, Rudemiller et al. 2014, Zhang et al. 2014). Decreased EET levels and increased $\mathrm{SEH}$ activity have been demonstrated to contribute to vascular and kidney inflammation in hypertension (Fig. 2) (Manhiani et al. 2009, Node et al. 1999, Zhao et al. 2004). On the other hand, increasing EET levels or decreased sEH activity have been demonstrated to decrease inflammation and blood pressure in animal models of hypertension (Deng et al. 2011, Manhiani et al. 2009, Olearczyk et al. 2009). EETs have been demonstrated to decrease kidney macrophage infiltration in hypertension (Olearczyk et al. 2009, Zhao et al. 2004). Likewise, increasing EET levels in the kidney decrease interleukin-6 (IL-6), TNF- $\alpha$, and monocyte chemoattractant protein-1 (MCP-1) levels in animal models of hypertension (Campbell et al. 2017, Olearczyk et al. 2009, Zhao et al. 2004). These anti-inflammatory EET actions are mediated by downregulation of the transforming growth factor- $\beta 1$ (TGF- $\beta 1$ )/Smad3 signaling, inhibition of IKK activity, and nuclear factor- $\kappa \mathrm{B}$ activation (Imig 2012,
Manhiani et al. 2009, Node et al. 1999). These findings indicate that $\mathrm{sEH}$ inhibition or increasing EET levels can decrease vascular and kidney inflammation to lower blood pressure in hypertension.

\section{Increasing epoxyeicosanoids lowers blood pressure and improves renal and cardiovascular outcomes in hypertension}

There have been two pharmacological approaches developed to manipulate EETs to lower blood pressure and combat cardiovascular morbidity and mortality in hypertension. The cardiovascular and renal actions of these pharmacological approaches agree with genetic approaches to increase EET levels (Campbell et al. 2017, Imig 2018, Imig and Hammock 2009, Yang et al. 2017). Antihypertensive actions were first demonstrated with sEH enzyme-based drugs in spontaneously hypertensive rats (SHR) and angiotensindependent hypertension (Imig et al. 2002, Yu et al. 2000). Several years later EET analogs that mimic the actions of endogenous EETs were demonstrated to lower blood pressure in SHR and angiotensin-dependent hypertension (Imig et al. 2010, Khan et al. 2014). The positive antihypertensive actions for $\mathrm{sEH}$ inhibitors and EET analogs have been attributed to anti-inflammation, vasodilation, and natriuresis (Fig. 3) (Campbell et al. 2017, Capdevila and Wang 2013, Imig 2012, Imig 2018, Imig and Hammock 2009). Details on the development of sEH inhibitors and EET analogs can be found in several exceptional review articles (Campbell et al. 2017, Capdevila and Wang 2013, Imig 2018, Imig and Hammock 2009, Marino 2009).

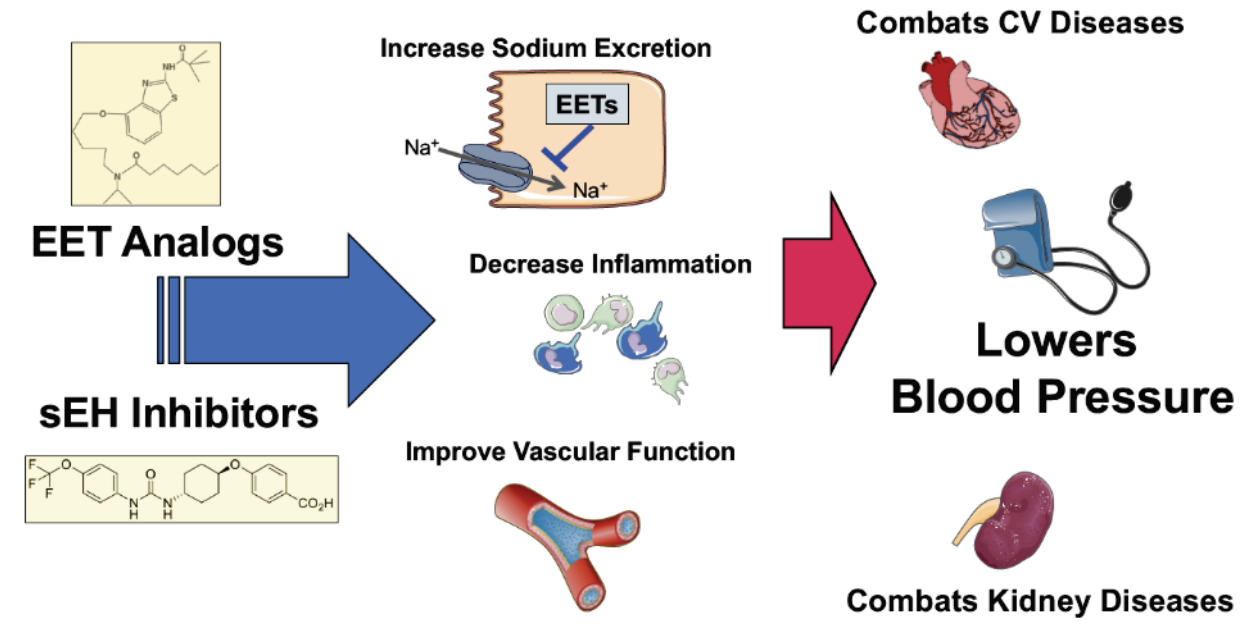

Fig. 3. Epoxyeicosatrienoic acid (EET) analogs and soluble epoxide hydrolase (sEH) inhibitors lowers blood pressure and combats cardiovascular (CV) and renal diseases. Left to right: EET analogs or sEH inhibitors increase sodium excretion, decrease inflammation, and improve vascular function to lower blood pressure and combat CV and renal diseases. 
Rapid development of sEH inhibitors resulted in the first human clinical trial and these $\mathrm{sEH}$ inhibitors continue to be tested in humans for beneficial cardiovascular actions (Imig and Hammock 2009). The positive kidney, heart, and vascular actions attributed to sEH inhibitors are associated with an increase in EET levels (Imig 2018, Imig and Hammock 2009, Marino 2009). A major advantage for sEH inhibitors was the early development of orally active inhibitors that allowed for chronic animal studies (Imig and Hammock 2009).

Experimental studies in animal models determined that sEH inhibitors or sEH (EPHX2) gene deletion were antihypertensive with vasodilatory and natriuretic actions (Imig et al. 2002, Manhiani et al. 2009, $\mathrm{Yu}$ et al. 2000, Zhao et al. 2003). Additional studies revealed that $\mathrm{sEH}$ inhibitors have anti-inflammatory and anti-fibrotic actions that decreases kidney and cardiac damage that occurs in hypertension (Imig 2018, Imig and Hammock 2009). Increasing epoxyeicosanoid levels via sEH inhibition improves the pressure-natriuretic relationship and attenuates angiotensin-dependent hypertension (Honetschlägerová et al. 2011a, Honetschlägerová et al. 2011b, Imig et al. 2002, Zhao et al. 2003). The blood pressure lowering action demonstrated by sEH inhibition in rats with angiotensin II malignant hypertension was due to an increase in renal EET levels and interactions with nitric oxide renal hemodynamic and sodium excretion actions (Honetschlägerová et al. 2013, Sporková et al. 2014, Varcabová et al. 2013). These studies revealed an interaction between sEH inhibition, EETs, and the renin-angiotensin system that contributes to the beneficial actions in hypertension (Sporková et al. 2014, Varcabová et al. 2013). Beneficial actions beyond lowering blood pressure have been observed with $\mathrm{sEH}$ inhibitors and EPHX2 gene deletion. Deoxycorticosterone acetate high salt (DOCA-salt) hypertension has a lower blood pressure in EPHX2 gene-deleted mice (Manhiani et al. 2009). In addition to blood pressure lowering in DOCA-salt hypertension, EPHX2 gene deletion attenuated kidney inflammation and glomerular injury (Manhiani et al. 2009). Inhibition of soluble epoxide hydrolase slows the progression of cardiac hypertrophy and renal tubulointerstitial and glomerular injury in 5/6 nephrectomized Ren-2 transgenic hypertensive rats (Kujal et al. 2014). These findings in kidney and cardiovascular disease animal models led to a rapid development for sEH inhibitors towards human clinical trials.

Human studies with sEH inhibitors have been variable in terms of ability to combat cardiovascular diseases (Imig and Hammock 2009, Yang et al. 2017). Initial clinical trials with sEH inhibitors evaluated type 2 diabetes and hypertension (Imig and Hammock 2009). Although efficacy was not established in the Phase II clinical trial, the sEH inhibitor was found to be safe to use and to inhibit sEH activity (Imig and Hammock 2009). More promising cardiovascular data were found in the second human clinical trial with sEH inhibitors (Yang et al. 2017). Forearm blood flow responses in obese humans with COPD indicated that endothelial dependent blood flow responses were improved (Yang et al. 2017). Several sEH inhibitor clinical trials are in various stages and include evaluating their therapeutic effects in subarachnoid hemorrhage (Imig 2018). Recent human studies also support the potential benefit for using $\mathrm{sEH}$ inhibitors to prevent or treat acute kidney injury following cardiac or thoracic surgeries (Shuey et al. 2017). Collectively, these findings indicate that $\mathrm{sEH}$ inhibitors are still a potential therapeutic for hypertension, kidney diseases, and cardiovascular diseases.

The development and testing of EET analogs has been slower due to hurdles in advancing to orally bioavailable EET analogs, multiple EETs with varied biological actions, and the lack of defined protein target (Campbell et al. 2017, Falck et al. 2014, Sudhahar et al. 2010). EET analog development has progressed based on structure activity relationship studies conducted in mesenteric resistance arteries, coronary arteries, and renal afferent arterioles (Campbell et al. 2017, Sudhahar et al. 2010). These studies led to 11,12-EET and 14,15-EET agonists and antagonists (Campbell et al. 2017, Falck et al. 2014). Subsequent modifications to the EET agonists resulted in orally bioavailable EET analogs (Campbell et al. 2017, Falck et al. 2014). These oral EET analogs were then tested in several hypertension and renal and cardiovascular disease animal models (Campbell et al. 2017).

Antihypertensive actions of EET analogs and genetic CYP2C expoxygenase overexpression were demonstrated in rat and mice hypertension models (Imig et al. 2010, Khan et al. 2014, Lee et al. 2010). EET analogs demonstrated an ability to lower blood pressure in SHR, angiotensin-dependent hypertension, and salt-sensitive hypertension (Campbell et al. 2017, Imig 2018). The decrease of blood pressure in response to 
EET analogs can be attributed to vasodilation and blocking epithelial sodium reabsorption (Khan et al. 2014). EET analogs attenuate the development of angiotensin-dependent malignant hypertension through suppression of angiotensin vasoconstriction and sodium reabsorption (Jíchová et al. 2016). On the other hand, EET analogs failed to lower blood pressure or attenuate end-organ damage when administered during the late malignant hypertension phase (Jíchová et al. 2016). Overexpressing epoxygenases in mouse endothelial cells results in increased endothelial EET synthesis, decreased blood pressure and decreased glomerular injury in angiotensin high salt hypertension (Lee et al. 2010). Cardiac beneficial actions for EET analogs have been determined in ischemic cardiac disease and hypertensioninduced cardiac hypertrophy (Batchu et al. 2011, Khan et al. 2013, Neckáŕ et al. 2018). The cardiac protective actions for EET analogs is due to vasodilatory, antifibrotic, and anti-inflammatory actions (Batchu et al. 2011, Khan et al. 2013, Neckář et al. 2018). Kidney protective actions have been determined in several acute and chronic kidney disease animal models (Campbell et al. 2017, Imig 2018). The EET analog, EET-A, lowered blood pressure, decreased the CXC chemotaxis inflammatory axis, and decreased renal fibrosis in female lupus nephritis mice (Khan et al. 2019). Overall, EET analogs have been widely demonstrated to decrease kidney disease progression in diabetes, hypertension, drug-induced nephrotoxicity, and radiation-induced kidney injury (Campbell et al. 2017, Imig 2018). The beneficial effects of EET analogs are a combination of improving endothelial function, decreasing renal inflammation, reducing apoptosis, and opposing epithelial to mesenchymal mediated fibrosis (Campbell et al. 2017, Imig 2018). Currently, EET analogs are moving towards clinical trials for kidney and cardiovascular diseases.

\section{Conclusions}

Epoxyeicosanoids have been extensively studied in hypertension and kidney and cardiovascular diseases associated with hypertension. These experimental studies in animal models and humans have demonstrated that decreased EET levels or increased sEH activity contributes to compromised endothelial and vascular function and epithelial sodium transport in hypertension
(Campbell et al. 2017, Imig 2015, Imig and Hammock 2009). Cardiovascular mortality and kidney damage associated with hypertension can also be attributed to decreases in epoxyeicosanoids (Campbell et al. 2017, Imig and Hammock 2009). Inflammation resulting from decreased EET levels contributes to these detrimental cardiovascular and kidney hypertension complications (Campbell et al. 2017, Imig and Hammock 2009). Pharmacological and genetic manipulation of $\mathrm{sEH}$, epoxygenase enzymes, and epoxyeicosanoid levels have determined that EETs dilate arterioles, decrease renal tubular sodium reabsorption, decrease fibrosis, and decrease inflammation (Campbell et al. 2017, Imig 2015, Imig and Hammock 2009). These epoxyeicosanoid actions not only contribute to blood pressure lowering in hypertension but also combat renal and cardiovascular disease (Campbell et al. 2017, Imig 2015, Imig and Hammock 2009). Likewise, the pharmacological development of sEH inhibitors and EET analogs demonstrates great potential including studies in humans to treat hypertension and associated complications (Campbell et al. 2017, Imig 2018). A recent study provides evidence that combining $\mathrm{sEH}$ inhibitors with EET analogs does not provide additive antihypertensive or cardioprotective effects in angiotensin-dependent hypertension (Červenka et al. 2018). This finding supports the notion that sEH inhibitors and EET analogs have overlapping actions to lower blood pressure and decrease renal and cardiovascular disease progression (Červenka et al. 2018). In conclusion, there is a bright future for $\mathrm{sEH}$ inhibitors or EET analogs as a treatment for hypertension and to combat cardiovascular mortality and kidney disease.

\section{Conflict of Interest}

Dr. Imig has patents that cover the composition of matter for EET analogs. There are no other conflicts of interest, financial or otherwise, are declared by the author.

\section{Acknowledgements}

This work was supported by the National Institute of Diabetes and Digestive and Kidney Diseases DK103616 and Dr. Ralph and Marian Falk Medical Research Trust Bank of America, N. A., Trustee. Servier Medical Art was used to generate Figures and is licensed by Servier under a Creative Commons Attribution 3.0 Unported License. 


\section{References}

BARRI YM: Hypertension and kidney diseases: a deadly connection. Curr Hypertens Rep 10: 39-45, 2008.

BATCHU SN, LEE SB, QADHI RS, CHAUDHARY KR, EL-SIKHRY H, KODELA R, FALCK JR, SEUBERT JM: Cardioprotective effect of a dual acting epoxyeicosatrienoic acid analogue towards ischaemia reperfusion injury. Br J Pharmacol 162: 897-907, 2011.

BAYLIS C: Nitric oxide synthase derangements and hypertension in kidney disease. Curr Opin Nephrol Hypertens 21: $1-6,2012$.

BELLIEN J, JOANNIDES R: Epoxyeicosatrienoic acid pathway in human health and diseases. $J$ Cardiovasc Pharmacol 61: 188-196, 2013.

BELLIEN J, IACOB M, REMY-JOUET I, LUCAS D, MONTEIL C, GUTIERREZ L, VENDEVILLE C, DREANO Y, MERCIER A, THUILLEZ C, JOANNIDES R: Epoxyeicosatrienoic acids contribute with altered nitric oxide and endothelin-1 pathways to conduit artery endothelial dysfunction in essential hypertension. Circulation 125: 1266-1275, 2012.

CAMPBELL WB, GEBREMEDHIN D, PRATT PF, HARDER DR: Identification of epoxyeicosatrienoic acids as endothelium-derived hyperpolarizing factors. Circ Res 78: 415-423, 1996.

CAMPBELL WB, IMIG JD, SCHMITZ JM, FALCK JR: Orally active epoxyeicosatrienoic acid analogs. $J$ Cardiovasc Pharmacol 70: 211-224, 2017.

CAPDEVILA J, WANG W: Role of cytochrome P450 exoxygenase in regulating renal membrane transport and hypertension. Curr Opin Nephrol Hypertens 22: 163-169, 2013.

CAPDEVILA JH, PIDKOVKA N, MEI S, GONG Y, FALCK JR, IMIG JD, HARRIS RC, WANG WH: The Cyp2c44 epoxygenase regulates epithelial sodium channel activity and the blood pressure responses to increased dietary salt. J Biol Chem 289: 4377-4386, 2014.

ČERVENKA L, HUSKOVÁ Z, KOPKAN L, KIKERLOVÁ S, SEDLÁKOVÁ L, VAŇOURKOVÁ Z, ALÁNOVÁ P, KOLÁř F, HAMMOCK BD, HWANG SH, IMIG JD, FALCK JR, SADOWSKI J, KOMPANOWSKAJEZIERSKA E, NECKÁŘ J: Two pharmacological epoxyeicosatrienoic acids-enhancing therapies effectively antihypertensive and reduce the severity of ischemic arrhythmias in rats with angiotensin II-dependent hypertension. J Hypertens 36: 1326-1341, 2018.

CHOBANIAN AV et al:: Seventh Report of the Joint Committee on Prevention, Definition, Evaluation and Treatment of High Blood Pressure. Hypertension 42: 1206-1256, 2003.

DENG Y, EDIN ML, THEKEN KN, SCHUCK RN, FLAKE GP, KANNON MA, DEGRAFF LM, LIH FB, FOLEY J, BRADBURY JA, GRAVES JP, TOMER KB, FALCK JR, ZELDIN DC, LEE CR: Endothelial CYP epoxygenase overexpression and soluble epoxide hydrolase disruption attenuate acute vascular inflammatory responses in mice. FASEB $J$ 25: 703-713, 2011.

DREISBACH AW, JAPA S, SIGEL A, PARENTI MB, HESS AE, SRINOUANPRACHANH SL, RETTIE AE, KIM H, FARIN FM, HAMM LL, LERTORA JJ: The Prevalence of CYP2C8, 2C9, 2J2, and soluble epoxide hydrolase polymorphisms in African Americans with hypertension. Am J Hypertens 18: 1276-1281, 2005.

FALCK JR, KODURU SR, MOHAPATRA S, MANNE R, ATCHA R, MANTHATI VL, CAPDEVILA JH, CHRISTIAN S, IMIG JD, CAMPBELL WB. 14,15-Epoxyeicosa-5,8,11-trienoic acid (14,15-EET) surrogates: carboxylate modifications. J Med Chem 57: 6965-6972, 2014.

FISSLTHALER B, POPP R, KISS L, POTENTE M, HARDER DR, FLEMING I, BUSSE R: Cytochrome P450 2C is an EDHF synthase in coronary arteries. Nature 401: 493-497, 1999.

HARRISON DG, GUZIK TJ, LOB HE, MADHUR MS, MARVAR PJ, THABET SR, VINH A, WEYAND CM. Inflammation, immunity, and hypertension. Hypertension 57: 132-140, 2011.

HONETSCHLÄGEROVA Z, HUSKOVÁ Z, VAŇOURKOVÁ Z, SPORKOVÁ A, KRAMER HJ, HWANG SH, TSAI HJ, HAMMOCK BD, IMIG JD, ČERVENKA L, KOPKAN L: Renal mechanisms contributing to the antihypertensive action of soluble epoxide hydrolase inhibition in REN-2 transgenic rats with inducible. J Physiol 589: 207-219, 2011a. 
HONETSCHLÄGEROVÁ Z, SPORKOVÁ A, KOPKAN L, HUSKOVÁ Z, HWANG SH, HAMMOCK BD, IMIG JD, KRAMER HJ, KUJAL P, VERNEROVÁ Z, ČERTÍKOVÁ CHÁBOVÁ V, TESAŘ V, ČERVENKA L: Inhibition of soluble epoxide hydrolase improves the impaired pressure-natriuresis relationship and attenuates the development of hypertension and hypertension-associated end-organ damage in Cyp1a1-Ren-2 transgenic rats. J Hypertens 29: 1590-1601, 2011 b.

HONETSCHLÄGEROVÁ Z, KITADA K, HUSKOVÁ Z, SPORKOVÁ A, KOPKAN L, BÜRGELOVÁ M, VARCABOVÁ A, NISHIYAMA A, HWANG SH, HAMMOCK BD, IMIG JD, KRAMER HJ, KUJAL P, VERNEROVÁ Z, ČERVENKA L: Antihypertensive and renoprotective action of soluble epoxide hydrolase inhibition in ANG II-dependent malignant hypertension are abolished by pretreatment with L-NAME. J Hypertens 31: 321-332, 2013.

IMIG JD: Epoxides and soluble epoxide hydrolase in cardiovascular physiology. Physiol Rev 92: 101-130, 2012.

IMIG JD: Epoxyeicosatrienoic acids, hypertension, and kidney injury. Hypertension 65: 476-482, 2015.

IMIG JD: Prospective for cytochrome P450 epoxygenase cardiovascular and renal therapeutics. Pharmacol Ther 192: 1-19, 2018.

IMIG JD, HAMMOCK BD: Soluble epoxide hydrolase as a therapeutic target for cardiovascular diseases. Nat Rev Drug Discov 8: 794-805, 2009.

IMIG JD, RYAN MJ: Immune and inflammatory role in renal disease. Compr Physiol 3: 957-976, 2013.

IMIG JD, INSCHO EW, DEICHMANN PC, REDDY KM, FALCK JR: Afferent arteriolar vasodilation to the sulfonimide analog of 11, 12-epoxyeicosatrienoic acid involves protein kinase A. Hypertension 33: 408-413, 1999.

IMIG JD, ZHAO X, CAPDEVILA JH, MORISSEAU C, HAMMOCK BD: Soluble epoxide hydrolase inhibition lowers arterial blood pressure in angiotensin II hypertension. Hypertension 39: 690-694, 2002.

IMIG JD, DIMITROPOULOU C, REDDY DS, WHITE RE, FALCK JR: Afferent arteriolar dilation to 11,12-EET analogs involves PP2A activity and $\mathrm{Ca}^{2+}$-activated $\mathrm{K}^{+}$Channels. Microcirculation 15: 137-150, 2008.

IMIG JD, ELMARAKBY A, NITHIPATIKOM K, WEI S, CAPDEVILA JH, TUNIKI VR, SANGRA B, ANJAIAH S, MANTHATI VL, REDDY DS, FALCK JR: Development of epoxyeicosatrienoic acid analogs with in vivo anti-hypertensive actions. Front Physiol 1: 157, 2010.

IMIG JD, KHAN MAH, EL-MEANAWY A: Molecular pathways in hypertensive damage. In: Disorders of Blood Pressure Regulation: Phenotypes, Mechanisms, Therapeutic Options, A. E. BERBARI, G. MANCIA (eds), Springer, Berlin, 2018, pp 445-463.

JÍCHOVÁ Š, KOPKAN L, HUSKOVÁ Z, DOLEŽELOVÁ S, NECKÁŘ J, KUJAL P, VERNEROVA Z, KRAMER HJ, SADOWSKI J, KOMPANOOWSKA-JEZIERSKA E, REDDY NR, FALCK JR, IMIG JD, ČERVENKA L: Epoxyeicosatrienoic analog attenuates development of malignant hypertension, but does not reverse it once established: a study in Cyp1a1-Ren-2 transgenic rats. J Hypertens 34: 2008-2025, 2016.

KAERGEL E, MULLER DN, HONECK H, THEUER J, SHAGDARSUREN E, MULLALLY A, LUFT FC, SCHUNCK WH:. P450-dependent arachidonic acid metabolism and angiotensin II-induced renal damage. Hypertension 40: 273-279, 2002.

KAPLAN NM: Treatment of hypertension: drug therapy. In: Clinical Hypertension, N. M. KAPLAN, J. T. FLYNN (eds), Lippincott Williams and Wilkins, Philadelphia, 2016, pp 217-230.

KHAN MAH, MANTHATI V, ERRABELLI R, PAVLOV TS, STARUSCHENKO A, FALCK JR, IMIG JD: An orally active epoxyeicosatrienoic acid analog attenuates kidney injury in hypertensive Dahl salt sensitive rat. Hypertension 62: 905-913, 2013.

KHAN MAH, PAVLOV TS, CHRISTIAN SV, NECKÁŘ J, STARUSCHENKO A, GAUTHIER KM, CAPDEVILA JH, FALCK JR, CAMPBELL WB, IMIG JD: Epoxyeicosatrienoic acid (EET) analog lowers blood pressure through vasodilation and sodium channel inhibition. Clin Sci(Lond) 127: 463-474, 2014.

KHAN MAH, STAVNIICHUK A, FALCK JR, MOHAMMAD AS, IMIG JD: Epoxyeicosatrienoic acid analog EET-A attenuates lupus nephritis in mice. Front Pharmacol 10: 512, 2019.

KING LM, GAINER JV, DAVID GL, DAI D, GOLDSTEIN JA, BROWN NJ, ZELDIN DC: Single nucleotide polymorphisms in the CYP2J2 and CYP2C8 genes and the risk of hypertension. Pharmacogenet Genomics 15: 7-13, 2005. 
KUJAL P, ČERTÍKOVÁ CHABOVÁ V, ŠKAROUPKOVÁ P, HUSKOVÁ Z, VERNEROVÁ Z, KRAMER HJ, WALKOWSKA A, KOMPANOWSKA-JEZIERSKA E, SADOWSKI J, KITADA K, NISHIYAMA A, HWANG SH, HAMMOCK BD, IMIG JD, ČERVENKA L: Inhibition of soluble epoxide hydrolase is renoprotective in 5/6 nephrectomized Ren-2 transgenic hypertensive rats. Clin Exp Pharmacol Physiol 41: 227-237, 2014.

LEE CR, IMIG JD, EDIN ML, FOLEY J, DEGRAFF LM, BRADBURY JA, GRAVES JP, LIH FB, CLARK J, MYERS P, PERROW AL, LEPP AN, KANNON MA, RONNEKLEIV OK, ALKAYED NJ, FALCK JR, TOMER KB, ZELDIN DC: Endothelial expression of human cytochrome P450 epoxygenases lowers blood pressure and attenuates hypertension-induced renal injury in mice. FASEB $J$ 24: 3770-3781, 2010.

LEE CR, PRETORIUS M, SCHUCK RN, BURCH LH, BARTLETT J, WILLIAMS SM, ZELDIN DC, BROWN NJ: Genetic variation in soluble epoxide hydrolase (EPHX2) is associated with forearm vasodilator responses in humans. Hypertension 57: 116-122, 2011.

MAKITA K, TAKAHASHI K, KARARA A, JACOBSON HR, FALCK JR, CAPDEVILA JH: Experimental and/or genetically controlled alterations of the renal microsomal cytochrome P450 epoxygenase induce hypertension in rats fed a high salt diet. $J$ Clin Invest 94: 2414-2420, 1994.

MANHIANI M, QUIGLEY JE, KNIGHT SF, TASOOBSHIRAZI S, MOORE T, BRANDS MW, HAMMOCK BD, IMIG JD: Soluble epoxide hydrolase gene deletion attenuates renal injury and inflammation with DOCA-salt hypertension. Am J Physiol Renal Physiol 297: F740-F448, 2009.

MARINO JP JR: Soluble epoxide hydrolase, a target with multiple opportunities for cardiovascular drug discovery. Curr Top Med Chem 9: 452-463, 2009.

MILLS KT, BUNDY JD, KELLY TN, REED JE, KEARNEY PM, REYNOLDS K, CHEN J, HE J. Global disparities of hypertension prevalence and control: a systematic analysis of population-based studies from 90 countries. Circulation 134: 441-450, 2016.

MONTEZANO AC, TOUYZ RM: Oxidative stress, Noxs, and hypertension: experimental evidence and clinical controversies. Ann Med $\mathbf{4 4}$ (Suppl 1): S2-S16, 2012.

MUNTNER P, DAVIS BR, CUSHMAN WC, BANGALORE S, CALHOUN DA, PRESSEL SL, BLACK HR, KOSTIS JB, PROBSTFIELD JL, WHELTON PK, RAHMAN M, ALLHAT COLLABORATIVE RESEARCH GROUP: Treatment-resistant hypertension and the incidence of cardiovascular disease and end-stage renal disease: results from the antihypertensive and lipid-lowering treatment to prevent heart attack trial (ALLHAT). Hypertension 64: 1012-1021, 2014.

NECKÁR̆ J, HSU A, HYE KHAN MA, GROSS GJ, NITHIPATIKOM K, CYPROVÁ M, BENÁK D, HLAVÁČKOVÁ M, SOTÁKOVÁ-KAŠPAROVÁ D, FALCK JR, SEDMERA D, KOLÁŘ F, IMIG JD: Infarct size-limiting effect of epoxyeicosatrienoic acid analog EET-B is mediated by hypoxia inducible factor$1 \alpha$ via down regulation of prolyl hydroxylase 3. Am J Physiol Heart Circ Physiol 315: H1148-H1158, 2018.

NODE K, HUO Y, RUAN X, YANG B, SPIECKER M, LEY K, ZELDIN DC, LIAO JK: Anti-inflammatory properties of cytochrome P450 epoxygenase-derived eicosanoids. Science 285: 1276-1279, 1999.

OLEARCZYK JJ, QUIGLEY JE, MITCHELL B, YAMAMOTO T, KIM IH, NEWMAN JW, LAURIA A, HAMMOCK BD, IMIG JD: Inhibition of the soluble epoxide hydrolase protects the kidney from damage in hypertensive Goto-Kakizaki rats. Clin Sci (Lond) 116: 61-70, 2009.

POLONIKOV AV, IVANOV VP, SOLODILOVA MA, KHOROSHAYA IV, KOZHUHOV MA, IVAKIN VE, KATARGINA LN, KOLESNIKOVA OE: A common polymorphism G-50T in cytochrome P450 2J2 gene is associated with increased risk of essential hypertension in a Russian population. Dis Markers 24: 119-126, 2008.

RUDEMILLER N, LUND H, JACOB HJ, GEURTS AM, MATTSON DL, PHYSGEN KNOCKOUT PROGRAM: CD247 modulates blood pressure by altering T-lymphocyte infiltration in the kidney. Hypertension 63: 559-564, 2014.

SHUEY MM, BILLINGS FT 4TH, WEI S, MILNE GL, NIAN H, YU C, BROWN NJ: Association of gain-of-function EPHX2 polymorphism Lys55Arg with acute kidney injury following cardiac surgery. PLoS One 12: e0175292, 2017. 
SPORKOVÁ A, JÍCHOVÁ S, HUSKOVÁ Z, KOPKAN L, NISHIYAMA A, HWANG SH, HAMMOCK BD, IMIG JD, KOMPANOWSKA-JEZIERSKA E, SADOWSKI J, KRAMER HJ, ČERVENKA L: Different mechanisms of acute versus long-term antihypertensive effects of soluble epoxide hydrolase inhibition: studies in Cyp1a1-Ren-2 transgenic rats. Clin Exp Pharmacol Physiol 41: 1003-1013, 2014.

SUDHAHAR V, SHAW S, IMIG JD: Epoxyeicosatrienoic acid analogs and vascular function. Curr Med Chem 17: 1181-1190, 2010.

SUN P, LIN DH, YUE P, JIANG H, GOTLINGER KH, SCHWARTZMAN ML, FALCK JR, GOLI M, WANG WH: High potassium intake enhances the inhibitory effect of 11,12-EET on ENaC. $J$ Am Soc Nephrol 21: 1667-1677, 2010.

VARCABOVÁ S, HUSKOVÁ Z, KRAMER HJ, HWANG SH, HAMMOCK BD, IMIG JD, KITADA K, ČERVENKA L: Antihypertensive action of soluble epoxide hydrolase inhibition in Ren-2 transgenic rats is mediated by suppression of the intrarenal renin-angiotensin system. Clin Exp Pharmacol Physiol 40: 273-281, 2013.

VIEL EC, LEMARIE CA, BENKIRANE K, PARADIS P, SCHIFFRIN EL: Immune regulation and vascular inflammation in genetic hypertension. Am J Physiol Heart Circ Physiol 298: H938-H944, 2010.

YANG L, CHERIYAN J, GUTTERMAN DD, MAYER RJ, AMENT Z, GRIFFIN JL, LAZAAR AL, NEWBY DE, TAL-SINGER R, WILKINSON IB: Mechanisms of vascular dysfunction in COPD and effects of a novel soluble epoxide hydrolase inhibitor in smokers. Chest 151: 555-563, 2017.

YU BN, LUO CH, WANG D, WANG A, LI Z, ZHANG W, MO W, ZHOU HH: CYP2C9 allele variants in Chinese hypertension patients and healthy controls. Clin Chim Acta 348: 57-61, 2004.

YU Z, XU F, HUSE LM, MORISSEAU C, DRAPER AJ, NEWMAN JW, PARKER C, GRAHAM L, ENGLER MM, HAMMOCK BD, ZELDIN DC, KROETZ DL: Soluble epoxide hydrolase regulates hydrolysis of vasoactive epoxyeicosatrienoic acids. Circ Res 87: 992-998, 2000.

ZHANG J, PATEL MB, GRIFFITHS R, MAO A, SONG YS, KARLOVICH NS, SPARKS MA, JIN H, WU M, LIN EE, CROWLEY SD: Tumor necrosis factor- $\alpha$ produced in the kidney contributes to angiotensin II-dependent hypertension. Hypertension 64: 1275-1281, 2014.

ZHAO X, POLLOCK DM, INSCHO EW, ZELDIN DC, IMIG JD: Decreased renal cytochrome P450 2C enzymes and impaired vasodilation are associated with salt-sensitive hypertension. Hypertension 41: 709-714, 2003.

ZHAO X, YAMAMOTO T, NEWMAN JW, KIM IH, WATANABE T, HAMMOCK BD, STEWART J, POLLOCK JS, POLLOCK DM, IMIG JD: Soluble epoxide hydrolase inhibition protects the kidney from hypertensioninduced damage. J Am Soc Nephrol 15: 1244-1253, 2004.

ZHAO X, DEY A, ROMANKO O, STEPP DW, WANG MH, JIN L, POLLOCK JS, WEBB RC, IMIG JD: Decreased epoxygenase and increased epoxide hydrolase expression in the mesenteric artery of obese Zucker rats. Am J Physiol Regul Integr Comp Physiol 288: R188-R196, 2005. 